\begin{tabular}{c} 
Volume and Issues Obtainable at Center for Sustainability Research and Consultancy \\
Journal of Business and Social Review in Emerging Economies \\
ISSN: 2519-089X (E): 2519-0326 \\
Volume 5: No. 1, June 2019 \\
CSRᄃ \\
Journal homepage: www.publishing.globalcsrc.org/jbsee \\
\hline
\end{tabular}

\title{
Factors Affecting the Demand for Mountain Biking at Putrajaya Challenge Park, Putrajaya
}

\author{
${ }^{1}$ Nur Syuhada Che Ibrahim, ${ }^{2}$ Syamsul Herman Mohammad Afandi, ${ }^{3}$ Zaiton Samdin \\ ${ }^{1}$ School of Social and Economic Development, University Malaysia Terengganu, Malaysia, \\ nursyuhadacheibrahim@gmail.com \\ ${ }^{2}$ Institute of Tropical Forestry and Forest Products, Putra Infoport, Universiti Putra Malaysia , \\ syamsulherman@gmail.com \\ ${ }^{3}$ Institute of Tropical Forestry and Forest Products, Putra Infoport, Universiti Putra Malaysia, \\ zaisa@putra.upm.edu.my
}

\begin{tabular}{l}
\multicolumn{1}{c}{ ARTICLE DETAILS } \\
\hline History \\
Revised format: May 2019 \\
Available Online: June 2019 \\
\\
\hline Keywords \\
Adventure Recreation, Mountain \\
Biking, Putrajaya Challenge Park
\end{tabular}

JEL Classification:

$Q 18, Q 19$

\section{ABSTRACT}

The popularity of Mountain Biking (MTB) in Malaysia is increasing.This adds to the demand for more cycling sites and special events for MTB. In line the growing demand, the Malaysian government encourages participation in active sports and recreation as a healthy lifestyle. One of the approaches is through the establishment of the Putrajaya Challenge Park (PCP). This study is conducted at PCP, one of a well-known MTB site in Malaysia. It has a network of treks where these treks are rated with different difficulty level for cyclists to choose from according to their abilityandpreferences. MTB is known to be associated with risks and high technical skills, hence it is great interest to understand the factors affecting demand in such sport. Therefore, the purpose of this study is to determine the factors affecting the demand in MTB participation at PCP. Data was collected using a structured questionnaire and obtained a total of 302 usable questionnaires. A multiple linear regression analysis is employed and it is found that three factors were significant at $95 \%$ confidence level; total travel cost, years of participation and cost of equipment upgrades. The finding from the study is to supply PCP management with the information for future adventurous recreational events in PCP or in other similar establishments. This research also identifies some key findings and makes some recommendations for future research and management.

(C) 2019 The authors, under a Creative Commons AttributionNonCommercial 4.0

Corresponding author's email address: nursyuhadacheibrahim@ gmail.com

Recommended citation: Ibrahim, N. S. C., Afandi, S. H. M. and Samdin, Z. (2019). Factors Affecting the Demand for Mountain Biking at Putrajaya Challenge Park, Putrajaya. Journal of Business and Social Review in Emerging Economies, 5 (1), 149-154

DOI: $10.26710 /$ jbsee.v5i1.616

\section{Introduction}

Malaysia is experiencing an increasing participation in an adventurous recreational activity; Mountain Biking (MTB). For that reason, the Malaysian government encourages the participation in sports and recreation through the launching active sports-related programmes and also the development of appropriate facilities. MTB is a physically active and vigorous type of recreational activity and which suit to be categorised as adventurous recreational 
activity. Adventure recreation is a form of recreational activities that contain structural components of real or perceived danger and usually involve a natural environment setting in which the outcome is uncertain but influenced by the participant (Ewert and Hollenhorst, 1997). As for details, MTB can be described as cycling focusing primarily on off-road travel and it is an environmentally sustainable and quiet activity that gives the rider a physical and enjoyable outdoor experience (Mountain Bikers of Santa Cruz, 2007).The popularity of MTB has grown substantially over the last 25 years and continues to grow Chiu \&Kriwoken (2003) and the growing popularity in such recreation has captured the government attention to establish a proper infrastructure to suit this type of activities. One of the developments is the Putrajaya Challenge Park (PCP), well-equipped for a number of popular extreme activities in the country that include Mountain Biking (MTB), Bicycle Motor Cross (BMX), Skate Boarding and Wall Climbing (WC). However, this study only focuses on MTB.Although MTB associated with risk, many people enjoy these unique activities to get the thrilling experience from the activity. While many take part in MTB to practice their skill, there are also individual who engaged in these activities for the purpose of exchanging techniques with others and for whatever reason, all of these are the benefit that a person might get upon engaging in recreational activity (Haskell, 1987; Gurin\& Harris, 1985).

The recreational demand function for a particular site is a relationship between the number of trips taken by an individual in a given period of time and trip price (travel cost), site characteristics and personal preferences or characteristics (Chakraborty and Keith, 2000). This demand correlation has been used to forecast visitation rate to the site and to estimate social welfare associated with the site and/or changes in site characteristics (Chakraborty and Keith, 2000). Hence, inthis study, the demand for MTB in PCP is specified by regressing the dependent variable (visit per year) and the identified exploratory variables.

\section{Materials and Methods}

This section deals with the methodology in the study that comprise of three sub sections.

\subsection{Study Area}

Putrajaya Challenge Park (PCP) offers customized facilities for extreme recreation in Malaysia. It was developed by Putrajaya Holdings with the cost of RM38 million and is currently operated by Putrajaya Corporation in collaboration with the Extreme Sports Association Malaysia (ESAM). PCP is well-equipped with facilities for adventure recreational activities particularly Mountain Biking (MTB). It covers an area of about 30.33 hectares and is located in Precint 5, Putrajaya. It has a network of MTB trails that passes through an oil palm and rubber plantation, secondary forests as well as bushes and grassy areas on hilly slopes.

\subsection{Instruments}

Instruments are essential in acquiring information, analyzing data and recording the findings and therefore are imperative in any research work (Sulaiman, 2004). In this study, questionnaire survey was used and the data for this research were obtained from a series of on-site surveys conducted at PCP. The target group for the survey was those who participate in MTB and likely to be using cycling treks and facilities at PCP. The survey was conducted by the researcher herself with the help of field assistants. Convenience sampling was applied and the sampling period was on Saturday and Sunday starting from $8.00 \mathrm{am}$ to $3.00 \mathrm{pm}$. The total final count of the usable sample was 302. Data collected are analyzed using SPSS version 20.0.

\subsection{Multiple Regression Analysis}

Multiple linear regression analysis is applied to determine the factors influencing the demand in MTB. The functional model for this study is shown in Equation 1.

Vij $=\beta 0+\beta 1$ TTraCost $+\beta 2$ EquipCost $+\beta 3$ YearsParticipate $+\beta 4$ BenefitIndex $+\beta 5$ AltsiteCost $+\beta 6$ OnSiteTime + $\beta 7$ Age $+\beta 8$ Income $+\beta$ Y YearsEdu $+\varepsilon i$

Equation 1

Where:

Vij

TTraCost

EquipCost

YearsParticipate
: Number of visits by individual $i$ to site $\mathrm{j}$ in a year

: Total Travel cost to the site including opportunity cost for travelling to PCP

: Equipment upgrades cost (Ringgit Malaysia)

: Years of participation in MTB (Years) 
BenefitIndex

AltsiteCost

OnSiteTime

Age

MonthlyIncome

YearsEdu
: Mean score for benefit in MTB

: Cost for travelling from home to alternative site for 2 ways(Ringgit Malaysia)

: Time taken for MTB at PCP (Hours)

: Age of the respondent (Years)

: Income of respondent in a month (Ringgit Malaysia)

: Years of education of the respondent (Years)

\section{Results and Discussions}

This section discusses about the result for this paper. It consists of two parts; descriptive statistics of mountain bikers and factors affecting demand for MTB at PCP

\subsection{Descriptive Statistics}

Descriptive statistics of the variables used in this studyin term of means, median, standard deviations (SD), minimum and maximum are presented in Table 1. The mean forvisit per year is 16 times, suggesting high participation frequency in PCP.Similar findings were also observed in previous studies; Green (2003), Koepke(2005), and Reiter and Blahna(2002). The mean total travel cost is found to be RM65.90, which is relatively low. This is due to the fact that most of the participants come from areas near to the PCP (Table 2). Mean for years of participation in MTB is 29 months (equivalent to 2 years and 5 months) suggesting the participants are experienced cyclist.Mean alternative site cost is RM8.90 while for on-site time is RM3.60. The average age is found to be 31 years old. The average for monthly income is RM3329.80. Mean for years of education is 14 years indicating that most of the users are those receiving university or college education. According to Bammel (1982), education was one of the factors influencing people to take part in recreation. People with education are generally aware of the benefits upon participation in recreational activity. The mean cost of equipment upgrades is RM1635.80 which is relatively expensive for a recreation activity.Since many of MTB gears are imported and of high quality most of it, is generally expensive. Nevertheless, in spite of the high price, it is acceptable for many MTB cyclists due to its safety and comfort of the equipment.

\section{Table 1: Descriptive statistics}

\begin{tabular}{|l|l|l|l|l|l|}
\hline Variables & Mean & Median & $\begin{array}{l}\text { Std. } \\
\text { Deviation }\end{array}$ & Minimum & Maximum \\
\hline Trip demand/year (Times) & 16.00 & 8.00 & 32.00 & 1.00 & 365.00 \\
\hline Total travel cost (RM) & 65.90 & 55.00 & 42.30 & 0.30 & 424.30 \\
\hline Years of participation (months) & 29.00 & 24.00 & 34.00 & 1.00 & 324.00 \\
\hline Alternative site cost (RM) & 8.90 & 7.25 & 7.60 & 0.30 & 48.45 \\
\hline On site time (Hours) & 3.60 & 3.00 & 1.30 & 1.00 & 8.00 \\
\hline Age (Years) & 31.00 & 30.00 & 6.00 & 17.00 & 58.00 \\
\hline Monthly income (RM) & 3329.80 & 3000.00 & 2202.30 & 100.00 & 12000.00 \\
\hline Years of education (Years) & 14.00 & 14.00 & 2.79 & 6.00 & 19.00 \\
\hline Cost of equipment upgrades (RM) & 1635.80 & 1000.00 & 1933.00 & 0.00 & 9500.00 \\
\hline
\end{tabular}

Participants to PCP come from various place of origin. Table 2 shows that residents of Selangor form the largest percentage of participants to PCP (70.5\%), followed by participants from Kuala Lumpur (14.6\%) and those from Putrajaya $(9.3 \%)$ while other states contributed smaller proportions of participants.

\section{Table 2: Origin of the mountain bikers}

\begin{tabular}{|l|l|l|}
\hline State Of Origin & Number & $\%$ Of Total \\
\hline Selangor & 213 & 70.5 \\
\hline Kuala Lumpur & 44 & 14.6 \\
\hline Putrajaya & 28 & 9.3 \\
\hline Negeri Sembilan & 13 & 4.3 \\
\hline Melaka & 2 & 0.6 \\
\hline Pahang & 1 & 0.3 \\
\hline Johor & 1 & 0.3 \\
\hline
\end{tabular}




\begin{tabular}{|l|l|l|}
\hline Total & 302 & 100.0 \\
\hline
\end{tabular}

\subsection{Factors affecting Demand for MTB at PCP}

Table 3 reports the result of multiple linear regression analysis. The determination coefficient, R2, measures the proportion of the variation in the dependent variable explained bythe independent variables and is found to be 0.368 indicating that only $36.8 \%$ of the variation in the MTB participation in this study is explained by the independent variables.From this study, three factors are foundto be significant at $95 \%$ confidence level. The variables aretotal travel cost, years of participation in MTB and equipment upgrades cost. The other variables includes alternative site cost, on-site time, monthly income, age, years of education are found to be not significant. According to Gadja (2008), it has been observed that factors such as marital status, occupation and income do not have any influence on frequency of participation in mountain biking.

Total travel cost is found to be inversely related to the demand of MTB. This implies that frequency of participation increases with low expenses in travel cost. The coefficient of the variable (-0.071) indicates that 0.071 of the standard deviation in the frequency of participation (dependent variable) is expected to decrease when the total travel cost (independent variable) increases by one standard deviation while holding all the other independent variables constant. Lesser expenditure in travel cost indicates nearer place of origin to PCP. This means that those who lived nearer would have more MTB sessions in PCP than those who are living further. This is supported by the fact that majority of the participants lived in Selangor, a neighbouring state to Putrajaya.

Years of participation is found directly proportionate towards dependent variable as shown by positive coefficient. The coefficient of the variable (6.487) indicates that 6.487 of standard deviation in the demand in MTB are expected to increase when years of participation increases by one standard deviation while holding all the other independent variables constant. MTB involves technical riding skill which also correlates to experience level. In general, participants with higher skills are more likely to commit in such activities since they are more experienced and have more knowledge in controlling and minimising risk. Those who have involved in MTB longer relatively are more experienced that newer cyclist. Ewert and Hollenhurst (1989) indicated that commitment includes participant with high level of skills, experience and commitment to the activity as they were prepared to face considerable risks in an environment that was unpredictable.

The relationship between equipment upgrades cost with frequency participation is found to be directly proportional. The coefficient of the variable (0.002) indicates that 0.002of the standard deviation in the frequency of MTB participation is expected to increase when equipment upgrades cost increases by one standard deviation while holding all the other independent variables constant. This result indicates that cyclist will increase their MTB activity when the have upgraded their cycling equipment. It is because new upgraded equipment would have better quality and more comfortable during cycling. It also shows that the willingness to invest more on equipments is the indicator of an increasing commitment in MTB with increasing experience level (Cessford, 1995).

Table 3: Multiple Regression Output

\begin{tabular}{|l|l|l|l|}
\hline Variable & $\beta$ & t-value & Sig. \\
\hline Constant & 2.356 & 0.775 & 0.439 \\
\hline Total Travel cost (Ringgit Malaysia) & -0.071 & -2.017 & $0.045^{*}$ \\
\hline Years of participation in MTB (Years) & 6.487 & 11.898 & $0.000^{*}$ \\
\hline Cost of equipment upgrades (Ringgit Malaysia) & 0.002 & 2.424 & $0.016^{*}$ \\
\hline
\end{tabular}

$\mathrm{R}$ square, $\mathrm{R} 2=0.368, \mathrm{R}=0.606, \mathrm{~F}=57.761$

* Significant at 0.05 confidence level

\section{Conclusion}

This study is successful in determining the factors affecting the demand in MTB participation at PCP.In the study, people participation in MTB is determined by three factors; distance to PCP, experience level of cyclist and the quality of equipment. As PCP is located at residential area, the majority of user would be from the vicinity areas. The commitment of the cyclist is evidence by the expenditure in upgrading, while experienced cyclist are more committed. These are the elements that can be considered by the management of PCP in relation to MTB. 
Additional research is proposed to better understand on the determinants of the demand in other adventure activities at PCP such as Skateboarding, Bicycle motor-cross and Wall climbing.

\section{Acknowledgements}

The authors would like to thank the research assistants who gathered and helped in data collection. This study was financed by a grant from Research University Grant Scheme (RUGS) Project Number 03-01-11-1158RU. All remaining errors and omissions in this paper are solely ours.

\section{References}

Bammel, G. and Bammel, L. L. (1982). Leisure and Human Behavior. Leisure Education Journal, 21, 455-460.

Cessford, G. (1995). Off-Road Mountain Biking: A profile of participants and their recreation setting and $\begin{array}{lllll}\text { experience } \quad \text { preferences. } & \text { Retrieved 2013, }\end{array}$ fromhttp://www.mountainbike.co.nz/politics/doc/profile/index.htm

Chakraborty, K. and Keith, J. E. (2000) Estimating the Recreation Demand and Economic Value of Mountain Biking in Moab, Utah: An Application of Count Data Models, Journal of Environmental Planning and Management, 43 (4), 461-469.

Chiu, L. and Kriwoken, L. (2003).Managing recreational mountain biking in Wellington Park, Tasmania, Australia. Annals of Leisure Research, 6 (4), 339-361.

Ewert, A.W. andHollenhurst, S. J.(1989). Testing the adventure model: empirical support for a model of risk recreation participation. Journal of Leisure Research, 21(2), 124-139.

Ewert, A.W. and Hollenhorst, S. (1997). Adventure Recreation and Its Implications for Wilderness.International Journal of Wilderness, 3(2), 21-26.

Gajda,M. S. (2008). U.K. Mountain Biking Tourism: An Analysis of Participant Characteristics, Travel Patterns And Motivations In The Context Of Activity And Adventure Tourism, Masters Dissertation, Napier University.

Green, D. (2003). Travel Patterns of Destination Mountain Bikers. International Mountain Biking Association. Retrieved on February 4, 2013,from

http://old.imba.com/resources/science/travel_patterns.html

Gurin, J. and Harris, T. G. (1985). Look who's getting it all together'. American Health Journal, 4(2), 42-47.

Haskell, W. L. (1987). Developing an activity plan for improving health, Exercise and Mental Health', Washington: Hemisphere Publishing Corporation Press.

Koepke, J. (2005). Exploring the Market potential for Yukon Mountain Bike Tourism. Retrieved on January 18, 2013, fromhttp://www.PotentialforMtnBikeTourismYT2004yukoncanada.pdf

Mountain Bikers of Santa Cruz (2007, July).Economic Benefits of Mountain Bike Tourism for Santa Cruz County. Retrieved on January 16, 2013,from

http://www.mbosc.org/2007/07/2007.07.economic_benefits_mtb_tourism_sc-v2.pdf

Reiter, D. K. and Blahna, D. J. (2002). Slickrock Trail Mountain Bike Survey: Implications for resource managers and area communities. Utah Recreation and Tourism Matters: Institute for Outdoor Recreation and Tourism. Retrieved onJanuary 23, 2013,from

http://extension.usu.edu/files/publications/publication/NR_RF_012.pdf

Sulaiman, S. (2004). Research Methods for social sciences made simple. Selangor, Malaysia: DSS Publishing Enterprise. 